\title{
Structural disorder of graphite and implications for graphite thermometry
}

\author{
Martina Kirilova ${ }^{1}$, Virginia Toy ${ }^{1}$, Jeremy S. Rooney ${ }^{2}$, Carolina Giorgetti $^{3}$, Keith C. Gordon ${ }^{2}$, Cristiano Collettini $^{3}$, \\ and Toru Takeshita ${ }^{4}$ \\ ${ }^{1}$ Department of Geology, University of Otago, P.O. Box 56, Dunedin 9054, New Zealand \\ ${ }^{2}$ Department of Chemistry, University of Otago, P.O. Box 56, Dunedin 9054, New Zealand \\ ${ }^{3}$ Dipartimento di Scienze della Terra, Università degli Studi La Sapienza, Rome, Italy \\ ${ }^{4}$ Faculty of Science, Earth and Planetary Sciences, Hokkaido University, Sapporo, Japan
}

Correspondence: Martina Kirilova (martina.a.kirilova@gmail.com)

Received: 11 July 2017 - Discussion started: 20 July 2017

Revised: 22 December 2017 - Accepted: 21 January 2018 - Published: 27 February 2018

\begin{abstract}
Graphitization, or the progressive maturation of carbonaceous material, is considered an irreversible process. Thus, the degree of graphite crystallinity, or its structural order, has been calibrated as an indicator of the peak metamorphic temperatures experienced by the host rocks. However, discrepancies between temperatures indicated by graphite crystallinity versus other thermometers have been documented in deformed rocks. To examine the possibility of mechanical modifications of graphite structure and the potential impacts on graphite "thermometry", we performed laboratory deformation experiments. We sheared highly crystalline graphite powder at normal stresses of 5 and 25 megapascal (MPa) and aseismic velocities of 1,10 and $100 \mu \mathrm{m} \mathrm{s}^{-1}$. The degree of structural order both in the starting and resulting materials was analyzed by Raman microspectroscopy. Our results demonstrate structural disorder of graphite, manifested as changes in the Raman spectra. Microstructural observations show that brittle processes caused the documented mechanical modifications of the aggregate graphite crystallinity. We conclude that the calibrated graphite "thermometer" is ambiguous in active tectonic settings.
\end{abstract}

\section{Introduction}

Organic matter, preserved in sedimentary rocks, can be transformed into crystalline graphite due to structural and compositional changes during diagenesis and metamorphism, a process known as graphitization (Bonijoly et al., 1982; Wopenka and Pasteris, 1993; Beyssac et al., 2002a, b, 2003; Buseck and Beyssac, 2014; etc.). Graphitization is thought to be an irreversible process and graphite is known to remain stable to the highest temperatures of granulite facies and the highest pressures of coesite-eclogite facies (Buseck and Beyssac, 2014). It is generally accepted that the degree of graphite crystallinity, or its structural order, is determined mainly by the maximum temperature conditions experienced by the host rocks, whereas lithostatic pressure and shear strain are considered to have only minor influence on graphitization (Bonijoly et al., 1982; Wopenka and Pasteris, 1993; Bustin et al., 1995). Therefore, graphite crystallinity has been calibrated as an indicator of the peak temperatures reached during progressive metamorphism (Beyssac et al., 2002a; Reitmeijer and McKinnon, 1985). However, in strained rocks discrepancies between temperatures indicated by the crystallinity of graphite vs. other thermometers have been reported (Barzoi, 2015; Nakamura et al., 2015; Kirilova et al., 2017). Thus, numerous authors have speculated that tectonic deformation results in graphite structural modifications that challenge the validity of the existing graphite thermometers (Large et al., 1994; Bustin et al., 1995; Crespo et al., 2006; Barzoi, 2015; Nakamura et al., 2015).

Furthermore, graphite occurrence and enrichment have been documented in several fault zones in the world e.g. the Alpine Fault zone, New Zealand (Kirilova et al., 2017), the Hidaka metamorphic belt, Hokkaido, Japan (Nakamura et al., 2015), the Atotsugawa fault system, Japan (Oohashi et al., 2012), the Tanakura Tectonic Line, Japan (Oohashi et al., 
2011), the Err Nappe detachment fault, Switzerland (Manatschal, 1999), and the KTB borehole, Germany (Zulauf et al., 1990). In these intensely deformed rocks its presence is of particular interest because its low friction coefficient of $\mu \sim 0.1$ (Morrow et al., 2000) allows graphite to act as a natural solid lubricant (Savage, 1948). The mechanical behavior of graphite has been broadly investigated in both natural and experimental specimens, where it manifests with the lowest $\mu$ among sheet structure minerals (Moore and Lockner, 2004; Oohashi et al., 2011, 2013; Rutter et al., 2013; Kuo et al., 2014 , etc.), confirming it could have a significant impact on fault mechanics. It has been experimentally proven that even a small fraction of graphite can have a disproportionally large effect on frictional strength where graphite is concentrated by smearing into interlinked layers (Rutter et al., 2013).

However, structural changes in crystalline graphite caused by tectonic deformation have not yet been systematically explored. To examine this aspect and to investigate the potential impacts of structural disordering of graphite on the graphite thermometer, we have carried out laboratory deformation experiments on highly crystalline graphite powder.

\section{Experimental methods}

\subsection{Sample description}

As a starting material in the current study we used synthetic (commercially synthesized) graphitic carbon to avoid complexities arising from a variable degree of crystallinity in natural carbon materials. Initially, the material was crushed to average grain size of $100 \mu \mathrm{m}$ in a Rocklabs swing (TEMA) mill. The resulting fine graphitic powder was annealed at $700^{\circ} \mathrm{C}$ for 2 hours in a Lindberg Blue M muffle furnace to achieve full graphitization, which is known to occur at this temperature in the absence of other variations in physical conditions (Buseck and Beyssac, 2014). This was used as the starting material for the deformation experiments.

\subsection{Experimental procedure}

In total, 10 deformation experiments were performed at room temperature and room humidity in the Brittle Rock deformAtion Versatile Apparatus (BRAVA) (Collettini et al., 2014), at the INGV, Rome. For each experiment two $3 \mathrm{~mm}$ - thick layers of synthetic graphite gouges were placed in between three grooved forcing blocks in a double-direct shear configuration (Dieterich, 1972). The two side blocks are held stationary and the central forcing block is driven downward causing shearing to occur within the graphite gouge layers. Normal stress is applied by the horizontal piston in load feedback control mode and shear displacement is accomplished when the vertical piston is in displacement-feedback control mode. Forces are measured with stainless steel load cells $( \pm 0.03 \mathrm{kN})$ and displacements are measured with linear variable differential transformers(LVDT) $( \pm 0.1 \mu \mathrm{m})$ at- tached to each piston. Experiments have been conducted at normal stresses of 5 or $25 \mathrm{MPa}$ and aseismic sliding velocities of 1,10 and $100 \mu \mathrm{m} \mathrm{s}^{-1}$. The experiments were carried out to total displacements of $20 \mathrm{~mm}$. In addition, some experiments were stopped at 5 and $10 \mathrm{~mm}$ and the specimens were then recovered to reveal graphite structural changes that took place during different amounts of total deformation. The coefficient of friction $(\mu)$ was calculated as the ratio of measured shear load to measured normal load $\left(\mu=\tau / \sigma_{\mathrm{n}}\right.$, where $\tau$ is shear stress and $\sigma_{\mathrm{n}}$ is effective normal stress). The average shear strain within the layer was calculated by dividing shear displacement increments by the measured layer thickness and summing it up. The displacement values of the vertical and horizontal load points were corrected for the elastic stretch of each load frame, taking into account that the machine stiffness is $1283 \mathrm{kN} \mathrm{mm}^{-1}$ on the horizontal axis and $928.5 \mathrm{kN} \mathrm{mm}^{-1}$ on the vertical axis. In addition, we calculated total frictional work for each experiment as a function of shear stress integrated over the total displacement (Beeler, 2007).

\subsection{Raman microspectroscopy}

Raman spectra of graphite were measured by an Alpha 300 $\mathrm{R}+$ confocal Raman microscope (WITec, Ulm, Germany) with a $532 \mathrm{~nm}$ laser (Coherent, Santa Clara, California), located at the Department of Chemistry, University of Otago, New Zealand. The laser $(3.0 \mathrm{~mW})$ was focused on the samples with a $50 \times$ Zeiss objective. The scattered light was dispersed with a $1200 \mathrm{~g} \mathrm{~mm}^{-1}$ grating. The combination of the $50 \times$ objective and $532 \mathrm{~nm}$ laser wavelength produced a laser spot size of approximately $412 \mathrm{~nm}$ in diameter. The integration time of each spectrum was $2 \mathrm{~s}$ with 50 co-additions ( $100 \mathrm{~s}$ in total). The spectra were calibrated using the Raman band from a silicon wafer prior to each set of measurements.

The collected spectra were pre-processed in Grams AI 9.1 (Thermo Fisher Scientific Inc.), where cosmic spikes were removed and a multi-point linear baseline offset was performed. This was followed by peak fitting three Lorentzian/Gaussian functions to each spectrum with a linear baseline over $1000-1700 \mathrm{~cm}^{-1}$. For each spectrum, the area ratio was calculated $\left(R 2=A_{\mathrm{D} 1} /\left(A_{\mathrm{G}}+A_{\mathrm{D} 1}+A_{\mathrm{D} 2}\right)\right.$, where $A i$ is the area of the $i$ th peak, G band is the main high-frequency band of graphite, and D1 and D2 bands are defect bands observed in the first-order Raman spectrum of graphite) (Wopenka and Pasteris, 1993; Beyssac et al., 2002a).

\subsection{Scanning electron microscopy}

Microstructural analyses of the graphite gouge recovered from the biaxial apparatus were carried out using a scanning electron microscope (SEM). Some SEM images were acquired from the shiny surfaces of the graphite layers that had been parallel to the center and/or side forcing blocks 
(sections $Y-Z$ ), with a Zeiss Sigma field emission scanning electron microscope (VP FEG SEM) at the Otago Centre for Electron Microscopy (OCEM), University of Otago, New Zealand. The instrument was operated in variable pressure mode (VP) at $15 \mathrm{kV}$ using a working distance (WD) of 7-8 $\mathrm{mm}$ and a VP-mode secondary electron (VPSE) detector. In addition, polished thin sections cut perpendicular to the surface of contact with the center and side forcing blocks (sections $X-Z$ ) were imaged on a JEOL JSM-6510 SEM at the University of Potsdam, Germany, where high-resolution secondary electron images were collected at $20 \mathrm{kV}$ and a WD of $10 \mathrm{~mm}$.

\subsection{Transmission electron microscopy}

Transmission electron microscopy (TEM) was used for detailed microstructural characterization of the shiny surfaces. High-resolution TEM images were collected by using a JEM-2010 electron microscope, located at the University of Hokkaido, Sapporo, Japan. The instrument was operated at $200 \mathrm{kV}$ with LaB6 filament. TEM foils (with a size of $12 \times 5 \mu \mathrm{m}$ and thickness of $1 \mu \mathrm{m}$ ) milled by a focused ion beam (FIB) perpendicular to the shiny surface (sections $X-Z$ ) were placed on a carbon-coated film and examined by using a dual-axis tilting holder.

\section{Results}

\subsection{Mechanical data}

Our experiments allowed us to investigate graphite mechanical behavior and structural modifications under various sliding velocities, normal stresses and shear strain. These conditions are summarized in Table 1 . The estimated total frictional work for each experiment is shown in Table 2.

\subsubsection{Friction variations}

Over several millimeters of displacement, the friction coefficient shows a similar evolution trend in all experiments. On a plot of friction coefficient vs. displacement (Fig. 1a), the friction coefficient $(\mu)$ delineates a curve characterized by a rapid increase to an initial peak friction coefficient $\left(\mu_{\text {peak }}\right)$, followed by a subsequent exponential decay towards a steady-state friction coefficient $\left(\mu_{\mathrm{ss}}\right)$ over a slip- weakening distance. The shapes of the friction-displacement curves vary with the normal stress applied and are steeper for the experiments conducted at $25 \mathrm{MPa}$ than the ones at $5 \mathrm{MPa}$ (Fig. 1a) because the displacement required to achieve steady-state decreases at higher normal stress. In addition, the values of both $\mu_{\text {peak }}$ and $\mu_{\text {ss }}$ (Fig. 1a; Table 1) are significantly lower in the experiments at $25 \mathrm{MPa}\left(\mu_{\text {peak }}=\sim 0.4 ; \mu_{\mathrm{ss}}=\sim 0.1\right)$ than in the experiments at $5 \mathrm{MPa}\left(\mu_{\text {peak }}=\sim 0.5 ; \mu_{\mathrm{ss}}=\sim 0.2\right)$, where $\mu_{\mathrm{ss}}$ values were read at the end of each experiment. Plots of $\mu$ at all sliding velocities (Fig. 1a) show subtle vari- (a)

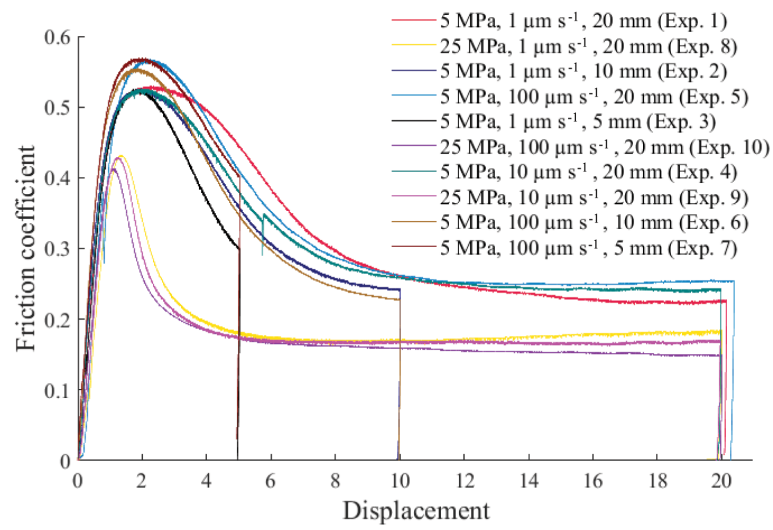

(b)

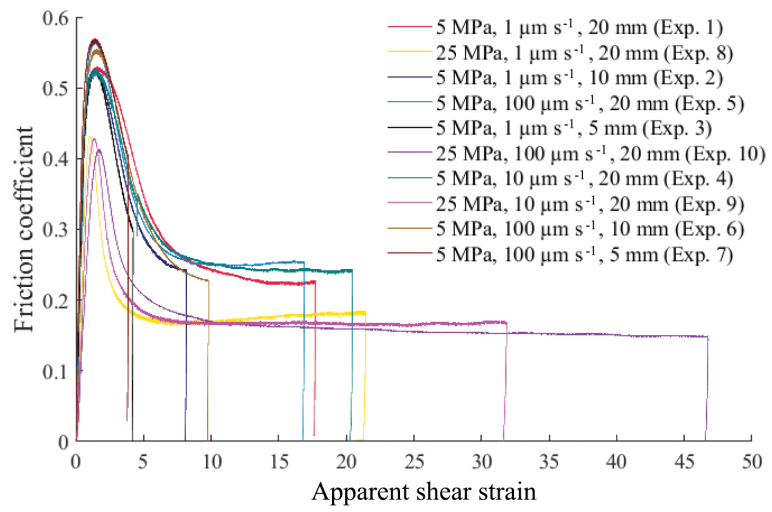

(c)

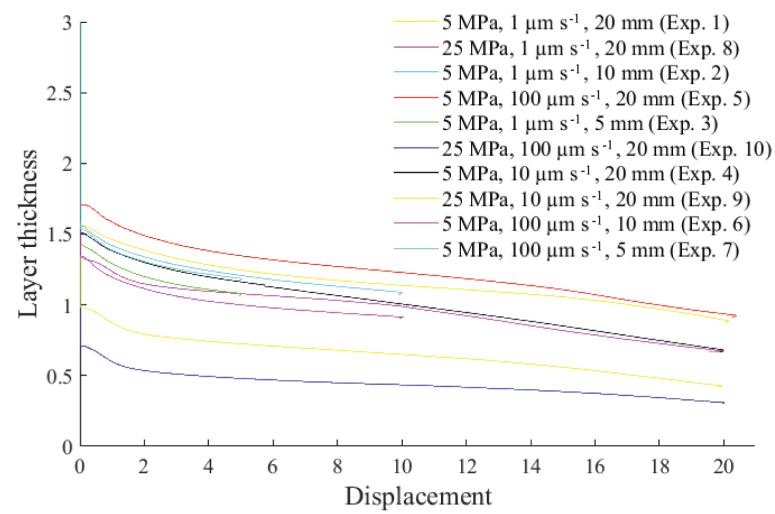

Figure 1. Plots of mechanical data: (a) friction coefficient $(\mu)$ vs. displacement; (b) friction coefficient ( $\mu$ ) vs. shear strain; (c) layer thickness vs. displacement.

ations in $\mu_{\text {peak }}$ and $\mu_{\mathrm{ss}}$ with a change in the applied sliding velocities (Fig. 1a; Table 1).

\subsubsection{Shear strain variations}

Plots of friction coefficient vs. shear strain (Fig. 1b) show significant variations in shear strain attained over equivalent sliding displacements. The estimated shear strain values are a geometric consequence of different thickness changes, which are visualized on plots of layer thickness vs. displacement (Fig. 1c). Consideration of the shear strain at equivalent sliding velocities but different normal stresses demonstrates that 
Table 1. Summary of the conditions at which experiments were carried out and results.

\begin{tabular}{|c|c|c|c|c|c|c|}
\hline $\begin{array}{l}\text { Experiment } \\
\text { number }\end{array}$ & $\begin{array}{r}\text { Normal } \\
\text { stress } \\
(\mathrm{MPa})\end{array}$ & $\begin{array}{r}\text { Sliding } \\
\text { velocity } \\
\left(\mu \mathrm{m} \mathrm{s}^{-1}\right)\end{array}$ & $\begin{array}{l}\text { Displacement } \\
(\mathrm{mm})\end{array}$ & $\begin{array}{r}\text { Peak friction } \\
\text { coefficient } \\
\left(\mu_{\text {peak }}\right)\end{array}$ & $\begin{array}{r}\text { Steady-state } \\
\text { friction } \\
\text { coefficient } \\
\left(\mu_{\mathrm{ss}}\right)\end{array}$ & $\begin{array}{r}\text { Shear } \\
\text { strain } \\
\text { maximum }\end{array}$ \\
\hline 1 & 5 & 1 & 20 & 0.53 & 0.22 & 17.70 \\
\hline 2 & 5 & 1 & 10 & 0.53 & 0.22 & 8.17 \\
\hline 3 & 5 & 1 & 5 & 0.52 & not reached & 4.23 \\
\hline 4 & 5 & 10 & 20 & 0.53 & 0.24 & 20.45 \\
\hline 5 & 5 & 100 & 20 & 0.57 & 0.22 & 16.89 \\
\hline 6 & 5 & 100 & 10 & 0.55 & 0.22 & 9.80 \\
\hline 7 & 5 & 100 & 5 & 0.57 & not reached & 3.87 \\
\hline 8 & 25 & 1 & 20 & 0.43 & 0.17 & 21.45 \\
\hline 9 & 25 & 10 & 20 & 0.43 & 0.17 & 31.86 \\
\hline 10 & 25 & 100 & 20 & 0.41 & 0.14 & 46.77 \\
\hline
\end{tabular}

shear strains achieved during the $5 \mathrm{MPa}$ experiments are approximately half of those at $25 \mathrm{MPa}$ (Fig. 1b; Table 1). In addition, the experiments at $25 \mathrm{MPa}$ demonstrate a dramatic increase in shear strain with increasing slip velocity (Fig. 1b; Table 1), whereas at low normal stress we do not observe any systematic variations associated with changes in sliding velocities (Fig. 1b, c and d).

\subsection{Raman spectra of graphite}

All the experiments resulted in the development of shiny smooth surfaces with gentle slickenlines (macroscopic fine grooves, parallel to the slip direction as defined by Toy et al., 2017). Raman spectra obtained on the top of the surfaces that had accommodated most of the induced deformation, are compared to Raman spectra from the starting material.

Raman data from 20 spectra per sample are presented in the Supplement (S1). Representative spectra for each sample are illustrated in Fig. 2, which shows spectra displaying the least (left column) and the most (right column) disordered graphite within a sample, i.e., lowest and highest $R 2$ values respectively. Spectra that were typical of the average for each sample are also presented (middle column). Experiments 3 and 7 were stopped at only $5 \mathrm{~mm}$ displacement and resulted in extremely fragile deformed surfaces, which were unable to be extracted without them breaking into pieces too small to obtain spectra from. Thus, Raman spectra were not measured in these experiments.

All the acquired spectra show typical G, D1 and D2 bands, respectively at $\sim 1580, \sim 1350$ and $\sim 1620 \mathrm{~cm}^{-1}$ (S1). Thus, we could calculate the area ratio $R 2$ for each spectrum (Fig. 2; S1). Raman spectra collected from the starting material show $R 2$ values ranging from 0 to 0.327 (Fig. 2; S1). Spectra acquired from the deformed surfaces show higher $R 2$ values (Fig. $2 ; \mathrm{S} 1$ ). The most ordered graphite with $R 2=0.330$ was collected in Exp. 2 (Fig. 2; S1) while the most disordered graphite with $R 2=0.661$ resulted from Exp. 10 (Fig. 2; S1).

As $R 2$ values vary within a sample (Fig. 2; S1), we examine average $R 2$ values for each one and compare them with applied normal stress, sliding velocity, shear strain and total frictional work (Table 2). The starting material has an average of $R 2$ pre-shear graphite $=0.173$, whereas all deformed samples have higher average $R 2$ values (Table 2). Analyzing the average $R 2$ values for deformed samples reveals that graphite is more disordered in the high normal stress experiments (Table 2) than in the experiments at $5 \mathrm{MPa}$. Furthermore, in the experiments at $25 \mathrm{MPa}$ the average $R 2$ increases with increasing sliding velocities (Table 2). In contrast, at low normal stress, we do not observe any dependence of the degree of graphite structural order on the applied sliding velocities (Table 2). Overall, graphite appears as most disordered in the experiments where the highest shear strain was achieved (Table 2). The relationship between average $R 2$ and shear strain is illustrated in Fig. 3a by fitting a power function with a correlation coefficient $R^{2}=0.95$. Fitting a power function to average $R 2$ and total frictional work did not show a consistent correlation (Fig. 3b). Experiments 2 and 6 at low normal stress, which were stopped at $10 \mathrm{~mm}$ displacement and accommodated the least amount of shear strain, contain the least disordered graphite (Fig. 3; Table 2).

\subsection{Microstructural characteristics}

\subsubsection{Scanning electron microscopy (SEM)}

Similar microstructural features were observed in all the deformed samples. SEM images obtained from the sample deformed during experiment 8 are presented to demonstrate our observations (Fig. 4).

These high-resolution images in sections $Y-Z$ reveal that the shiny surfaces are decorated by closely spaced (from $<5$ to 10 micrometers) slickenlines (Fig. 4a), on top of a smooth, 
Table 2. Summary of the relationship between shear strain, average $R 2$ and total frictional work within a sample. The conditions of each experiment are also given as follows: applied normal stress in $\mathrm{MPa}$, sliding velocities in $\mu \mathrm{m} \mathrm{s}^{-1}$ and sliding displacement in mm. $\mathrm{n} / \mathrm{a}-\mathrm{not}$ applicable.

\begin{tabular}{llrrr}
\hline Sample & Experimental conditions & $\begin{array}{r}\text { Shear } \\
\text { strain }\end{array}$ & $\begin{array}{r}\text { Average } R 2 \\
\text { (error estimate } \pm 0.05)\end{array}$ & $\begin{array}{r}\text { Total frictional } \\
\text { work }\end{array}$ \\
\hline Pre-shear graphite & $\mathrm{n} / \mathrm{a}$ & $\mathrm{n} / \mathrm{a}$ & 0.173 & \\
Exp. 2 & $5 \mathrm{MPa}, 1 \mu \mathrm{m} \mathrm{s}^{-1}, 10 \mathrm{~mm}$ & 8.17 & 0.438 & 17.711 \\
Exp. 6 & $5 \mathrm{MPa}, 100 \mu \mathrm{m} \mathrm{s}^{-1}, 10 \mathrm{~mm}$ & 9.80 & 0.430 & 17.7506 \\
Exp. 5 & $5 \mathrm{MPa}, 100 \mu \mathrm{m} \mathrm{s}^{-1}, 20 \mathrm{~mm}$ & 16.89 & 0.454 & 32.0578 \\
Exp. 1 & $5 \mathrm{MPa}, 1 \mu \mathrm{m} \mathrm{s}^{-1}, 20 \mathrm{~mm}$ & 17.70 & 0.506 & 25.885 \\
Exp. 4 & $5 \mathrm{MPa}, 10 \mu \mathrm{m} \mathrm{s}^{-1}, 20 \mathrm{~mm}$ & 20.45 & 0.517 & 30.5943 \\
Exp. 8 & $25 \mathrm{MPa}, 1 \mu \mathrm{m} \mathrm{s}^{-1}, 20 \mathrm{~mm}$ & 21.45 & 0.520 & 96.6089 \\
Exp. 9 & $25 \mathrm{MPa}, 10 \mu \mathrm{m} \mathrm{s}^{-1}, 20 \mathrm{~mm}$ & 31.86 & 0.580 & 92.4834 \\
Exp. 10 & $25 \mathrm{MPa}, 100 \mu \mathrm{m} \mathrm{s}^{-1}, 20 \mathrm{~mm}$ & 46.77 & 0.604 & 87.703 \\
\hline
\end{tabular}

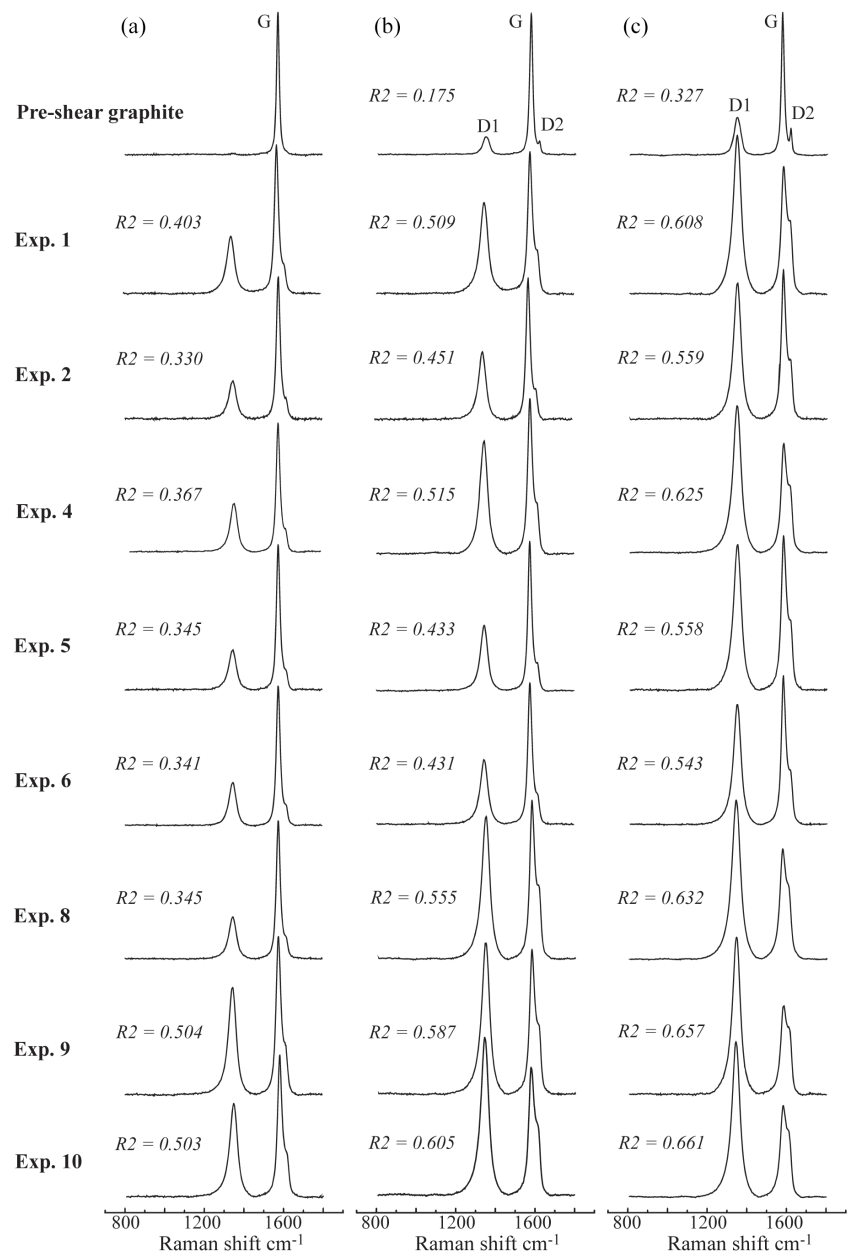

Figure 2. Representative Raman spectra illustrating (a) the most structurally ordered graphite within a sample; (b) graphite with average structural order per sample; (c) the most disordered graphite encountered in each sample. The $R 2$ ratio for each spectrum (with an error estimate \pm 0.05 ) is noted in italic font.
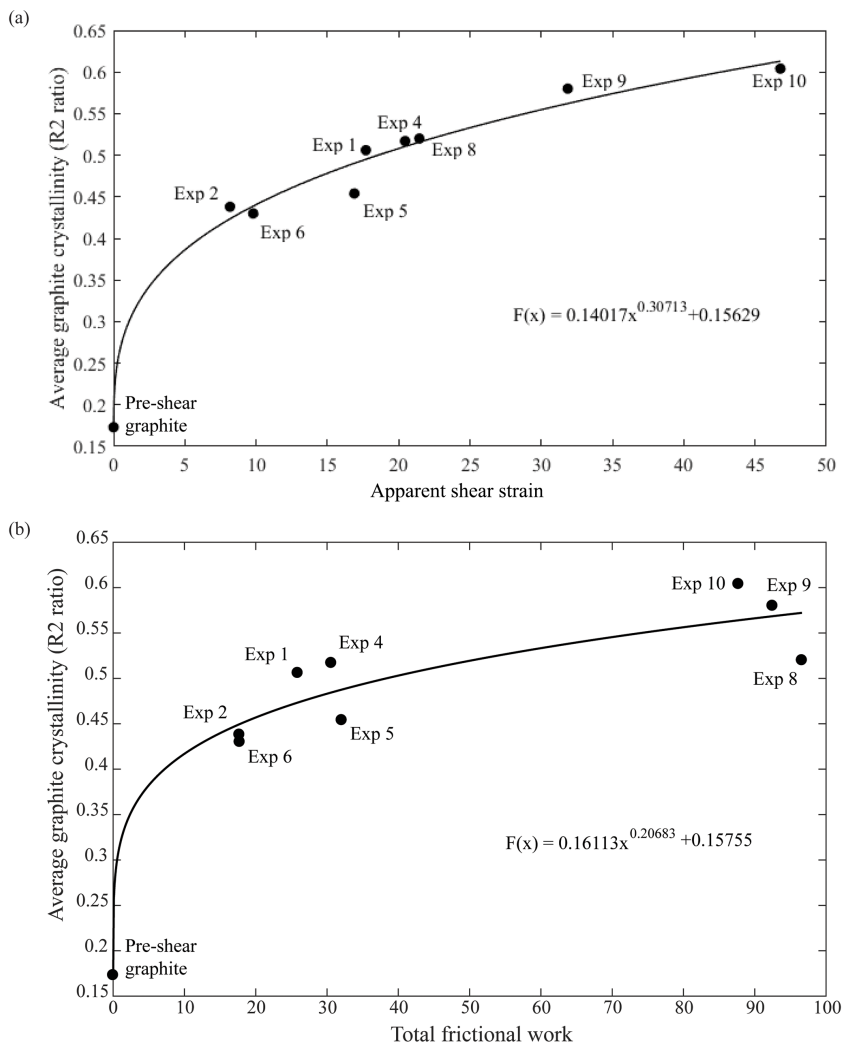

Figure 3. Plot of the average $R 2$ ratio per sample vs. (a) the apparent shear strain accumulated during each experiment, and (b) the total frictional work estimated for each experiment.

continuous layer. In places, the continuity of this layer is interrupted by fine ( $\sim 1$ to $2 \mu \mathrm{m}$ in width) fractures (Fig. 4a), with random orientation compared to the slip direction. Occasionally, the deformed surface appears as completely disrupted and is decorated with small graphite grains (from 50 to $<10 \mu \mathrm{m}$ in size), oriented nearly parallel to the shear direction (Fig. 4b). In sections $X-Z$, this highly deformed surface 


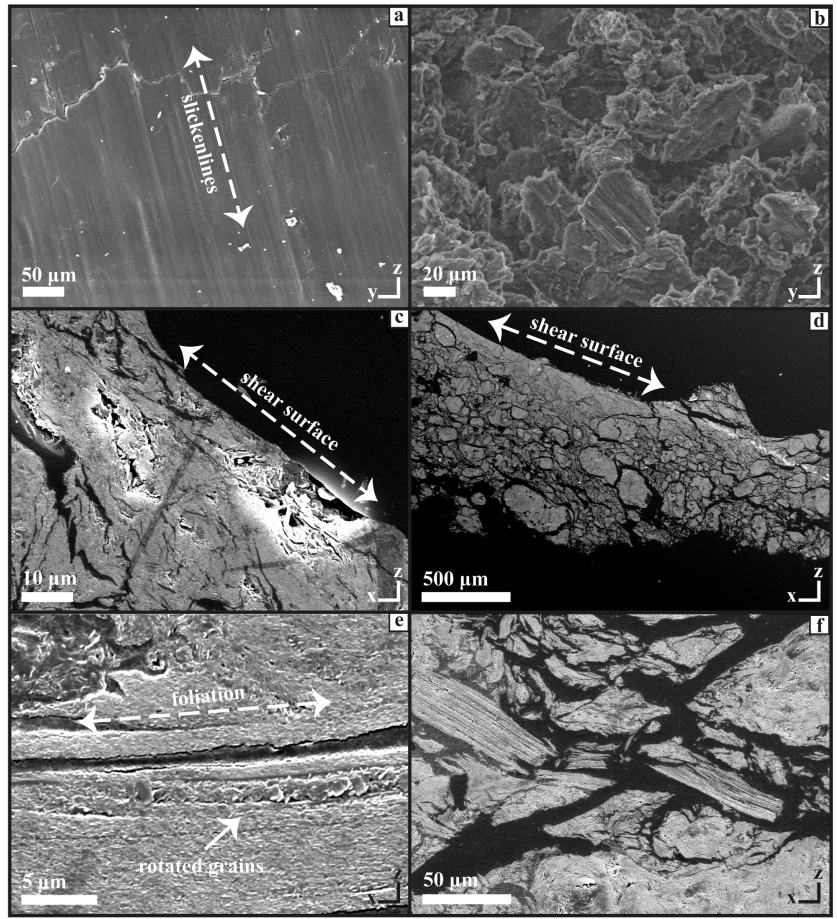

Figure 4. SEM images, obtained from the deformed graphite gouge during experiment 8 (normal stress at $25 \mathrm{MPa}$ with $1 \mu \mathrm{m} \mathrm{s}^{-1}$ sliding velocity), show the following: (a) slickenlines ornamenting the shear surface; $(\mathbf{b}, \mathbf{c})$ a well-compacted layer of aligned graphite grains, which make up the shear surface. Bright patches due to a differential charging effect; (d) a less deformed zone with typical cataclastic fabric, underlying the shear surface; (e) dilated cleavage planes in large graphite grains filled with smaller platy graphite grains oriented sub-perpendicular to the shear direction; (f) fractured graphite grains.

is observed as a thin slip-localized zone, composed of a wellcompacted layer of aligned graphite grains (Fig. 4c). This localized shear surface is underlain by a zone of randomly oriented, inequigranular, irregular graphite grains (Fig. 4d). In places, most of the graphite grains are aligned with their basal (001) planes parallel to the slip direction and form compacted layers, defining a weakly developed fabric (Fig. 4e). There has been some dilation along these cleavage planes and the spaces thus created are filled with smaller graphite grains with their (001) planes perpendicular to the shear direction (Fig. 4e). Locally, intensely fractured grains are also observed (Fig. 4f).

\subsubsection{Transmission electron microscopy (TEM)}

TEM was used to examine the microstructure of the material that makes up the shiny surfaces (Fig. 4c). TEM analyses were performed on foils cut perpendicular to this surface. Figure 5 shows characteristic TEM images obtained from the sample recovered from experiment 8 .
Graphite grains in this well-compacted layer have basal planes predominantly aligned with the shear plane, as were observed in the SEM images. However, adjacent grains show slightly different orientations (Fig. 5a). In addition, kinkfolded graphite grains are observed in multiple locations in the foils (Fig. 5b, c), which yields a "wavy layering" at a small angle to the shear direction (Fig. 5b). In isolated areas, there are also some smaller grain fragments with random orientation (Fig. 5d).

\section{Discussion}

\subsection{Mechanical behavior}

Graphite in our experiments shows mechanical behavior consistent with other mechanical studies of pure graphite gouges. Our results display low $\mu_{\mathrm{ss}}$ values (from $\sim 0.1$ to $\sim 0.2$; Table 1 ) as did the low-pressure deformation experiments of carbonaceous material performed by Morrow et al. (2000), Moore and Lockner (2004), Oohashi et al. (2011, 2013), Kuo et al. (2014) and Rutter et al. (2013). The low frictional strength of graphite is well known and has been attributed to its sheet structure composed of covalently bonded carbon atoms held together only by van der Waals forces. These weak interlayer bonds along (001) planes are easily broken during the shearing process (Moore and Lockner, 2004; Rutter et al., 2013). Initial $\mu_{\text {peak }}$ followed by strain weakening during deformation experiments of graphite gouges has been previously explained with the work involved in rotating the grains with their (001) planes sub-parallel to the shear surfaces, which puts them in the optimal position for shearing along the weak interlayer bonds (Morrow et al., 2000; Moore and Lockner, 2004; Rutter et al., 2013).

Plots of layer thickness vs. displacement (Fig. 1c) show that the initial compaction resulted in layers with different thickness prior to shearing. Therefore, we refer to the estimated shear strains (or the ratio of shear displacement to measured layer thickness) as apparent shear strains. Correlation between these values and the conditions of the experiments shows that the apparent shear strains are significantly higher in the experiments performed at $25 \mathrm{MPa}$ than the ones at $5 \mathrm{MPa}$, mainly due to better compaction of the sheared graphite gouges (Fig. 1c). The number of apparent shear strains rises with an increase in the applied sliding velocities in the high normal stress experiments (Fig. 1b). However, this trend also reflects differences in the layer thickness prior to shearing (Fig. 1c). The latter interpretation is also supported by the absence of similar correlation during the low normal stress experiments. Nevertheless, there are too few of these relationships to fully characterize the effect of normal stress and sliding velocity on shear strain accumulation in graphite gouges and more mechanical data of this sort need to be collected in the future. 


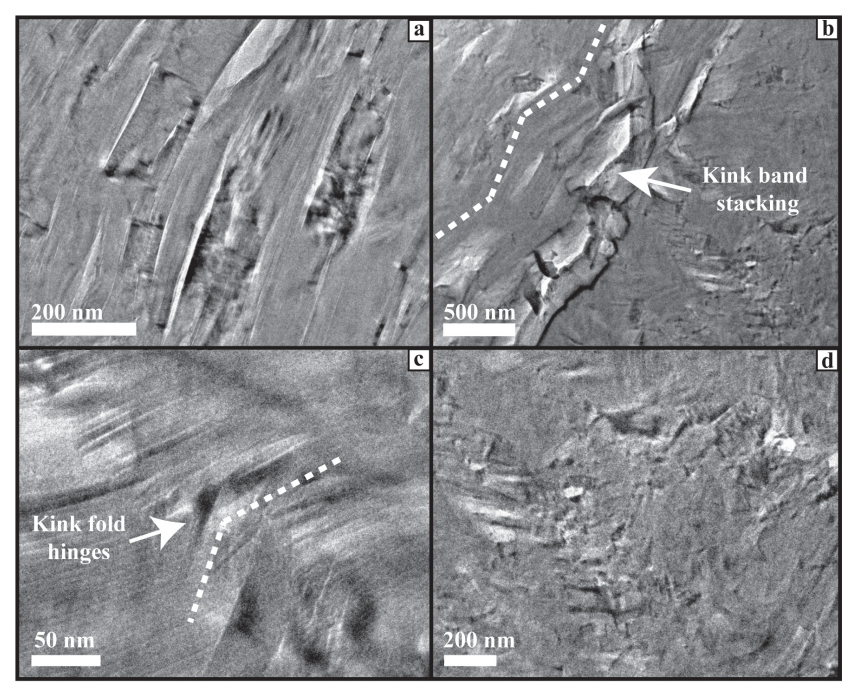

Figure 5. TEM images showing microstructural characteristics of the slip-localized shear surface: (a) aligned grains showing slightly different orientation; (b) kink band stacking; (c) dilated kink fold hinges; (d) fragmented grains.

\subsection{Structural disorder of graphite}

We evaluate the structural order of graphite by analyzing variations in $R 2$ ratios, which depend on the increase of defect bands (D1 and D2) in the Raman spectrum of graphite. Previous studies have documented increases in $R 2$ with decreasing degree of graphite crystallinity (Wopenka and Pasteris, 1993; Beyssac et al., 2002a, b). Therefore, our experimental study may demonstrate transformation of fully or highly crystalline graphite (with $R 2$ ratios ranging from 0 to 0.327 ; Fig. $2 ; \mathrm{S} 1$ ) into comparatively poorly organized graphitic carbon (with $R 2$ ratios up to 0.661 ; Fig. 2; S1). However, we do not have direct evidence suggesting intragranular deformation. Alternatively, the observed increase of defect bands is also likely to reflect an increase in the grainboundary density (Tunistra and Koening, 1970; Pimenta et al., 2007). The latter is further supported by our microstructural data that reveal the existence of fine graphite grains (ranging from $50 \mu \mathrm{m}$ to nm-scale grains; Figs. 4, 5) which are significantly smaller in size than the average grain size of the starting material $(100 \mu \mathrm{m})$. We interpret that shear deformation caused intense grain size reduction and hence an increase in the grain-boundary density, which was reflected in the Raman spectra. This suggests a decrease in the overall aggregate crystallinity rather than intragranular deformation of individual graphite grains.

We also acknowledge that the slickenlined surfaces that were produced experimentally contain some graphite that yield spectra comparable to those acquired from the starting material, that is, there is highly ordered graphite that appears as unaffected by the deformation. However, at least some of these spectra are derived from undeformed graphite powder that underlies the shear surfaces and could not be entirely removed during sample preparation due to the fragile nature of the samples. It is also possible that some non-deformed graphite powder was accidently measured through the fractures that are cross-cutting the accumulated shear surfaces (Fig. 4a). But even if some graphite did not undergo mechanical modification during the experiments, the results overall validate that structural disorder of graphite aggregates can result from shear deformation subsequent to the graphitization process.

To understand the potential causes for the documented structural disorder of graphite aggregates, we compared the measured average $R 2$ with the parameters of the performed experiments. Our data show a good correlation between the average $R 2$ and the apparent shear strain at the tested aseismic sliding velocities (Fig. 3). However, these bulk shear strains (Table 1) are likely to be significantly lower than the shear strains accommodated within the thin shear surface and so we refer to the above relationship as a rough approximation. Nevertheless, previous authors have also suspected that shear strain may play an important role for graphite modifications and evidence for this has been found in graphite crystallinity variations in natural samples from active fault zones (Kirilova et al., 2017; Nakamura et al., 2015) and strained rocks in metamorphic terrains (Barzoi, 2015; Large et al., 1994). Thus, we speculate that deformation may control the final structural order of graphite aggregates. Consequently, the previously proposed model of progressive graphitization due to an increase in temperature does not completely reflect the graphite formation mechanisms. (Bonijoly et al., 1982).

Our microstructural observations provide some indications of the deformation processes that affected structural disorder of graphite aggregates. The shiny slickenlined surfaces are composed of very fine-grained material visible as a sliplocalized zone on the SEM images (Fig. 4d). Nanoscale observations reveal graphite grains within it occasionally form stacked kink-band structures (Fig. 5b, c). This zone, which we assume accommodated most of the induced deformation, is underlined by a less deformed zone composed of larger graphite grains in a finer matrix that in places has developed as an anastomosing fabric, typical of creeping gouges (Fig. 4d). As seen through the SEM, brittelyfractured grains also occur in rare places (Figs. $4 \mathrm{f}$ and 5d). The interpreted structures suggest that brittle processes occurred during shearing and we conclude that these processes resulted in the structural disorder of graphite aggregates, manifested as changes in the Raman spectra. This interpretation is in agreement with the conditions of our experiments (i.e., shearing with aseismic velocities took place at room temperature conditions) that typically would not induce temperatures high enough for ductile processes. Furthermore, the microstructures and the inferred processes are exactly the same as those observed by Nakamura et al. (2015) in the Hidaka metamorphic belt, Japan. 
However, crustal fault zones do not only accommodate brittle deformation. At higher temperatures and confining pressures, localized shearing can operate by crystal plastic mechanisms (White et al., 1980). We hypothesize that graphite structural order could be influenced by ductile deformation, as was also suggested in previous studies by Large et al. (1994), Bustin et al. (1995), and Barzoi et al. (2015). Furthermore, Kuo et al. (2014) and Oohashi et al. (2011) simulated fault motions in synthetic and natural carbonaceous material with a variable degree of maturity at the start of the experiments (ranging from amorphous carbonaceous material to crystalline graphite). Both studies reported graphitization of carbonaceous material due to localized frictional heating rather than structural disordering. These experiments reveal the impact of seismic velocities on graphite structural order. The fact that their findings differ so markedly from ours further highlights the complexity of graphite transformations in fault zones.

\subsection{Implications for graphite thermometry}

The structural order of graphite measured by Raman spectroscopy has been applied as a thermometer that relies on progressive maturation of originally organic carbonaceous material during diagenesis and metamorphism. Previous studies have focused on calibrating this thermometer. The current best calibration is described by the following equation: $T\left({ }^{\circ} \mathrm{C}\right)=-445 \times R 2+641 \pm 50$ (Beyssac et al., 2002a) by inferring a linear correlation between the $R 2$ ratio and peak metamorphic temperatures. However, this thermometer disregards the effects of mechanical modifications on the structure of graphite aggregates, which this study has identified as having a substantial influence on the $R 2$ ratios in deformed graphite gouges at sub-seismic velocities.

Our experiments demonstrate an increase of the $R 2$ ratio of initially highly crystalline graphite powder due to brittle deformation (Fig. 3a; Table 2). In natural analogues, the preshear graphite would yield temperatures up to $641 \pm 50^{\circ} \mathrm{C}$ (S1), which is the upper limit of the calibrated thermometer (Beyssac et al., 2002a), whereas the sheared samples would indicate peak metamorphic temperatures as low as $347 \pm 50^{\circ} \mathrm{C}(\mathrm{S} 1)$. Thus, we experimentally prove that in active tectonic settings graphite thermometers may underestimate the peak metamorphic temperatures by $<300^{\circ} \mathrm{C}$. In cataclasites from the Alpine Fault zone, New Zealand (Kirilova et al., 2017) and fault zones of the Hidaka metamorphic belt, Japan (Nakamura et al., 2015), the graphite thermometer yields temperature discrepancies of more than $100^{\circ} \mathrm{C} \mathrm{com-}$ pared to temperature estimates derived both from the surrounding high-grade amphibolite facies mylonites and the lower- grade equilibrium cataclastic phases (marked by chlorite alteration). Barzoi (2015) also described differences of $\sim 150^{\circ} \mathrm{C}$ in graphite temperatures between strained and less strained low-grade metamorphic rocks from Parang Mountains, South Carpathians.
We conclude that the existing graphite thermometer is unreliable in active tectonic settings. Furthermore, a calibration of this thermometer may be impossible to achieve because both structural disorder of graphite and graphitization (Oohashi et al., 2013) are likely to be encountered in fault zones.

\section{Conclusions}

We have experimentally demonstrated structural disorder of graphite aggregates, manifested as changes in the Raman spectra, by shearing highly organized graphite powder at aseismic sliding velocities insufficient to generate appreciable frictional heat. Microstructural data presented here reveal that this is a result of brittle processes. Our findings clearly compromise the validity of the calibrated graphite thermometer by showing it may significantly underestimate the peak metamorphic temperatures in active tectonic settings.

Data availability. Due to the large number of data they are available upon request.

\section{The Supplement related to this article is available online at https://doi.org/10.5194/se-9-223-2018-supplement.}

Competing interests. The authors declare that they have no conflict of interest.

Acknowledgements. The research was funded by the Department of Geology, University of Otago, New Zealand and Rutherford Discovery Fellowship RDF-UOO0612 awarded to Virginia Toy. We also acknowledge the "Tectonics and Structure of Zealandia" subcontract to the University of Otago by GNS Science (under contract C05X1702 to the New Zealand Ministry of Business, Innovation and Employment). We thank our colleagues Gemma Kerr and Brent Pooley for assistance in sample preparation and Hamish Bowman for helping with data visualization. We also wish to express our gratitude to Laura Halliday for generously offering to perform grain size analysis on our samples at the Department of Geography, University of Otago, New Zealand. And last but not least, we thank Marco Scuderi for valuable discussions and assistance throughout the experimental procedures.

Edited by: Renée Heilbronner

Reviewed by: Oohashi Kiyokazu and Rüdiger Kilian

\section{References}

Barzoi, S. C.: Shear stress in the graphitization of carbonaceous matter during the low-grade metamorphism from the northern 
Parang Mountains (South Carpathians) - Implications to graphite geothermometry, Int. J. Coal Geol., 146, 179-187, 2015.

Beeler, N. M.: Laboratory-observed faulting in intrinsically and apparently weak materials: Strength, seismic coupling, dilatancy, and pore-fluid pressure, The Seismogenic Zone of Subduction Thrust Faults, 370-449, 2007.

Beyssac, O., Goffé, B., Chopin, C., and Rouzaud, J. N.: Raman spectra of carbonaceous material in metasediments: a new geothermometer, J. Metamorph. Geol., 20, 859-871, 2002a.

Beyssac, O., Rouzaud, J. N., Goffé, B., Brunet, F., and Chopin, C.: Graphitization in a high-pressure, low-temperature metamorphic gradient: a Raman microspectroscopy and HRTEM study, Contrib. Mineral. Petr., 143, 19-31, 2002b.

Beyssac, O., Brunet, F., Petitet, J. P., Goffé, B., and Rouzand, J. N.: Experimental study of the microtextural and structural transformations of carbonaceous materials under pressure and temperature, Eur. J. Mineral., 15, 937-951, 2003.

Bonijoly, M., Oberlin, M., and Oberlin, A.: A possible mechanism for natural graphite formation, Int. J. Coal Geol., 1, 283-312, 1982.

Buseck, P. R. and Beyssac, O.: From organic matter to graphite: Graphitization, Elements, 10, 421-426, 2014.

Bustin, R. M., Ross, J. V., and Rouzaud, J. N.: Mechanisms of graphite formation from kerogen: experimental evidence, Int. J. Coal Geol., 28, 1-36, 1995.

Collettini, C., Di Stefano, G., Carpenter, B., Scarlato, P., Tesei, T., Mollo, S., Trippetta, F., Marone, C., Romeo, G., and Chiaraluce, L.: A novel and versatile apparatus for brittle rock deformation, Int. J. Rock Mech. Min., 66, 114-123, 2014.

Crespo, E., Luque, F. J., Barrenechea, J. F., and Rodas, M.: Influence of grinding on graphite crystallinity from experimental and natural data: implications for graphite thermometry and sample preparation, Mineral. Mag., 70, 697-707, 2006.

Kirilova, M., Toy, V., Timms, N., Halfpenny, A., Menzies, C., Craw, D., Beyssac, O., Sutherland, R., Townend, J., Boulton, C., Carpenter, B., Cooper, A., Grieve, J., Little, T., Morales, L., Morgan, C., Mori, H., Sauer, K., Schleicher, A., Williams, J., and Craw, L.: Textural changes of graphitic carbon by tectonic and hydrothermal processes in an active plate boundary fault zone, Alpine Fault, New Zealand, in: Geological Society, London, Special Publication "Advances in the Characterization of Ore-Forming Systems from Geological, Geochemical and Geophysical data", edited by: Gessner, K., Blenkinsop, T. G., and Sorjonen-Ward, P., 453 SP453-13, 2017.

Kuo, L. W., Li, H., Smith, S. A., Di Toro, G., Suppe, J., Song, S. $\mathrm{R}$., and $\mathrm{Si}$, J.: Gouge graphitization and dynamic fault weakening during the $2008 \mathrm{Mw} 7.9$ Wenchuan earthquake, Geology, 42, 4750, 2014.

Large, D. J., Christy, A. G., and Fallick, A. E.: Poorly crystalline carbonaceous matter in high grade metasediments: implications for graphitisation and metamorphic fluid compositions, Contrib. Mineral. Petr., 116, 108-116, 1994.

Manatschal, G.: Fluid-and reaction-assisted low-angle normal faulting: evidence from rift-related brittle fault rocks in the Alps (Err Nappe, eastern Switzerland), J. Struct. Geol., 21, 777-793, 1999.
Moore, D. E. and Lockner, D. A.: Crystallographic controls on the frictional behavior of dry and water-saturated sheet structure minerals, J. Geophys. Res.-Sol. Ea., 109, B03401, https://doi.org/10.1029/2003JB002582, 2004.

Morrow, C. A., Moore, D. E., and Lockner, D. A.: The effect of mineral bond strength and adsorbed water on fault gouge frictional strength, Geophys. Res. Lett., 27, 815-818, 2000.

Nakamura, Y., Oohashi, K., Toyoshima, T., Satish-Kumar, M., and Akai, J.: Strain-induced amorphization of graphite in fault zones of the Hidaka metamorphic belt, Hokkaido, Japan, J. Struct. Geol., 72, 142-161, 2015.

Oohashi, K., Hiros, T., and Shimamoto, T.: Shear-induced graphitization of carbonaceous materials during seismic fault motion: experiments and possible implications for fault mechanics, J. Struct. Geol., 33, 1122-1134, 2011.

Oohashi, K., Hirose, T., and Shimamoto, T.: The occurrence of graphite-bearing fault rocks in the Atotsugawa fault system, Japan: origins and implications for fault creep, J. Struct. Geol., 38, 39-50, 2012.

Oohashi, K., Hirose, T., and Shimamoto, T.: Graphite as a lubricating agent in fault zones: An insight from low-to high-velocity friction experiments on a mixed graphite-quartz gouge, J. Geophys. Res.-Sol. Ea., 118, 2067-2084, 2013.

Pimenta, M. A., Dresselhaus, G., Dresselhaus, M. S., Cancado, L. G., Jorio, A., and Saito, R.: Studying disorder in graphite-based systems by Raman spectroscopy, Phys. Chem. Chem. Phys., 9, 1276-1290, 2007.

Rietmeijer, F. J. and Mackinnon, I. D.: Poorly graphitized carbon as a new cosmothermometer for primitive extraterrestrial materials, Nature, 315, 733-736, 1985.

Rutter, E. H., Hackston, A. J., Yeatman, E., Brodie, K. H., Mecklenburgh, J., and May, S. E.: Reduction of friction on geological faults by weak-phase smearing, J. Struct. Geol., 51, 52-60, 2013.

Savage, R. H.: Graphite lubrication, J. Appl. Phys., 19, 1-10, 1948.

Toy, V. G., Niemeijer, A. R., Renard, F. Wirth, R., and Morales, L.: Striation and slickenline development on quartz fault surfaces at crustal conditions: Origin and effect on friction, J. Geophys. Res.-Sol. Ea., 122, 3497-3512, https://doi.org/10.1002/2016JB013498, 2017.

Tuinstra, F. and Koenig, J. L.: Raman spectrum of graphite, J. Chem. Phys., 53, 1126-1130, 1970.

White, S. H., Burrows, S. E., Carreras, J., Shaw, N. D., and Humphreys, F. J.: On mylonites in ductile shear zones, J. Struct. Geol., 2, 175-187, 1980.

Wopenka, B. and Pasteris, J. D.: Structural characterization of kerogens to granulite-facies graphite: applicability of Raman microprobe spectroscopy, Am. Mineral., 78, 533-557, 1993.

Zulauf, G., Kleinschmidt, G., and Oncken, O.: Brittle deformation and graphitic cataclasites in the pilot research well KTB-VB (Oberpfalz, FRG), Geological Society, London, Special Publications, 54, 97-103, 1990. 